\title{
Endoscopic submucosal dissection of colonic lesions: first 50 cases at a local institution
}

\author{
Yee Shyn $\underline{T a i}^{1}$, MBBS, Clement LK $\underline{\text { Chia }}^{1}$, MBBS, FRCSEd, Kok-Yang $\underline{\operatorname{Tan}}^{1}$, MBBS, FRCSEd
}

\begin{abstract}
INTRODUCTION Endoscopic submucosal dissection (ESD) in the colon and rectum has been developed with good reported outcomes. The main advantage of ESD is the ability to perform en bloc resection, which has implications for complete excision and pathological analysis. Locally, the use of ESD in colonic lesions has seen recent traction. Our study aimed to review the outcomes of the first 50 cases of endoscopic excision of advanced colonic lesions using ESD at our institution.

METHODS This was a retrospective study of all patients who underwent ESD at our institution from September 2010 to October 2016. Data collected included patient demographics, resection technique, conversion rate and morbidity. RESULTS 51 patients underwent ESD during the study period. All patients were of American Society of Anesthesiologists (ASA) class $1-3$. Their median age was 60.0 years and the majority $(n=36)$ were male. The mean procedure time was 80.9 minutes. $36(76.6 \%)$ of cases underwent en bloc resection. $4(7.8 \%)$ cases required conversion to surgery, mainly due to difficulty in raising the colonic lesions. 3 (5.9\%) patients had malignancy as the final histology. 2 (4.3\%) patients had recurrence during surveillance scope. No cases of early mortality were reported.

CONCLUSION Our results suggest that ESD for advanced colonic lesions can be safely performed. Expertise needs to be developed to achieve satisfactory en bloc resection rates.
\end{abstract}

Keywords: colorectal tumours, endoscopic en bloc resection, endoscopic mucosal resection, endoscopic submucosal dissection

\section{INTRODUCTION}

The link between colorectal carcinoma (CRC) and adenoma is now well established. ${ }^{(1)}$ As such, the complete removal of these adenomas reduces the risk of developing CRC. Studies have shown that one of the main contributing factors for local recurrence is the incomplete resection of lesions. ${ }^{(2)}$ Large and sessile adenomas remain a challenge for complete excision and patients may undergo surgical resection instead. The development of endoscopic resection provided a less invasive option of removing lesions that cannot be snared by conventional methods. In particular, endoscopic mucosal resection (EMR) has emerged as a treatment for flat and sessile colonic polyps. ${ }^{(3)}$ However, EMR is not ideal for larger lesions, as the possibility of piecemeal resection is higher. This has implications for the completeness of the resection, pathological analysis and recurrence rates, thus affecting management and follow-up surveillance plans. ${ }^{(4)}$

Endoscopic submucosal dissection (ESD) was first described in the '90s by the Japanese in the context of gastric tumour removal. Aiming to achieve en bloc resection and lower local recurrence rates, endoscopists started applying this technique to colonic polyps. ${ }^{(5)}$ The five-year cancer recurrence rate following ESD was reported at $1.6 \%{ }^{(6)}$ Despite the advantages of ESD, EMR remains the more common technique in Western countries due to several reasons, one being the lack of training opportunities. ${ }^{(7)}$ Furthermore, ESD is technically more demanding and time-consuming due to the higher complication rates compared to EMR. ${ }^{(8)}$ Given the usefulness of ESD, this paper aimed to present our institution's experience of its first 50 cases of endoscopic resection of advanced colonic lesions using ESD.

\section{METHODS}

We reviewed the data of 51 patients who underwent endoscopic resection of colonic lesions using ESD. These resections were performed by a single endoscopist from September 2010 to October 2016. Patients who had polyps with the following characteristics were selected for endoscopic resection: broadbased, flat, and with pit or vascular patterns on magnified views suggestive of adenoma. These polyps were deemed not suitable for conventional snaring. Patient factors analysed were age, gender, American Society of Anesthesiologists (ASA) physical classification, resection techniques, types of resection, size and location of lesions, histology of lesions, rate of conversion to surgery and complication rates (Table I). Patients had a median age of 60.0 years and most were categorised as ASA 2.

Lesions that were not considered for endoscopic resection were those with strong suspicion of massive submucosal

Table I. Baseline characteristics of patients $(n=51)$.

\begin{tabular}{|ll|}
\hline Characteristic & No. \\
\hline Gender & \\
\hline Male & 36 \\
\hline Female & 15 \\
\hline Age* (yr) & $60.0(38-77)$ \\
\hline ASA score & \\
\hline Class 1 & 8 \\
\hline Class 2 & 38 \\
\hline Class 3 & 5 \\
\hline
\end{tabular}

*Data presented as median (range). ASA: American Society of Anesthesiologists 

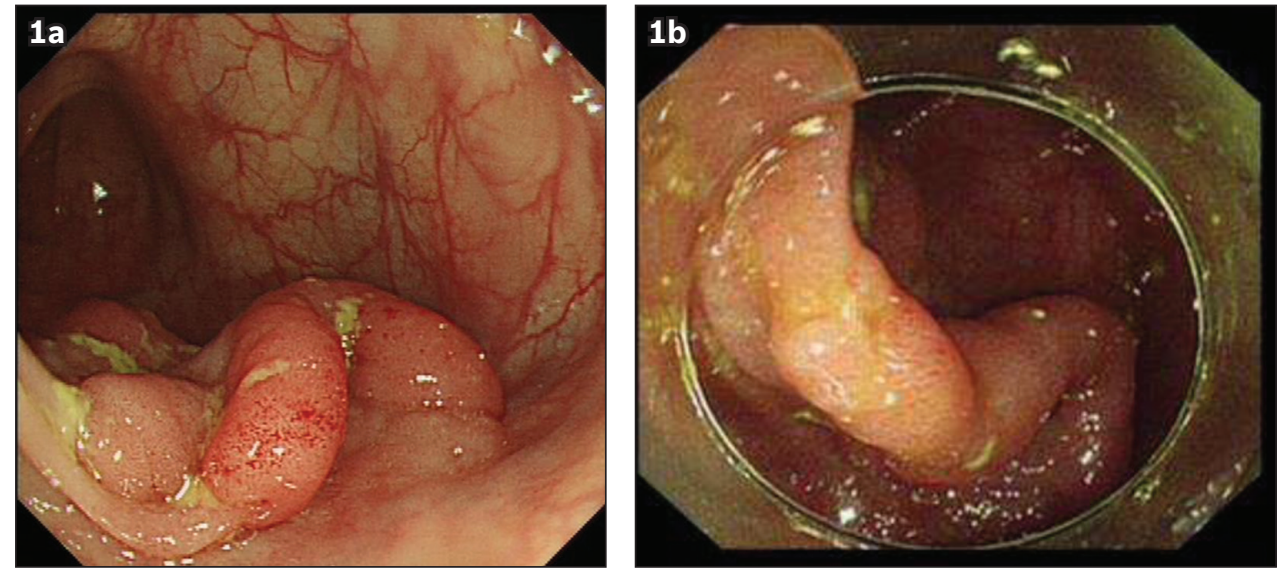

Fig. 1 Photographs shows broad-based transverse colon lesions in (a) initial endoscopic view and (b) prior to commencement of submucosal dissection.
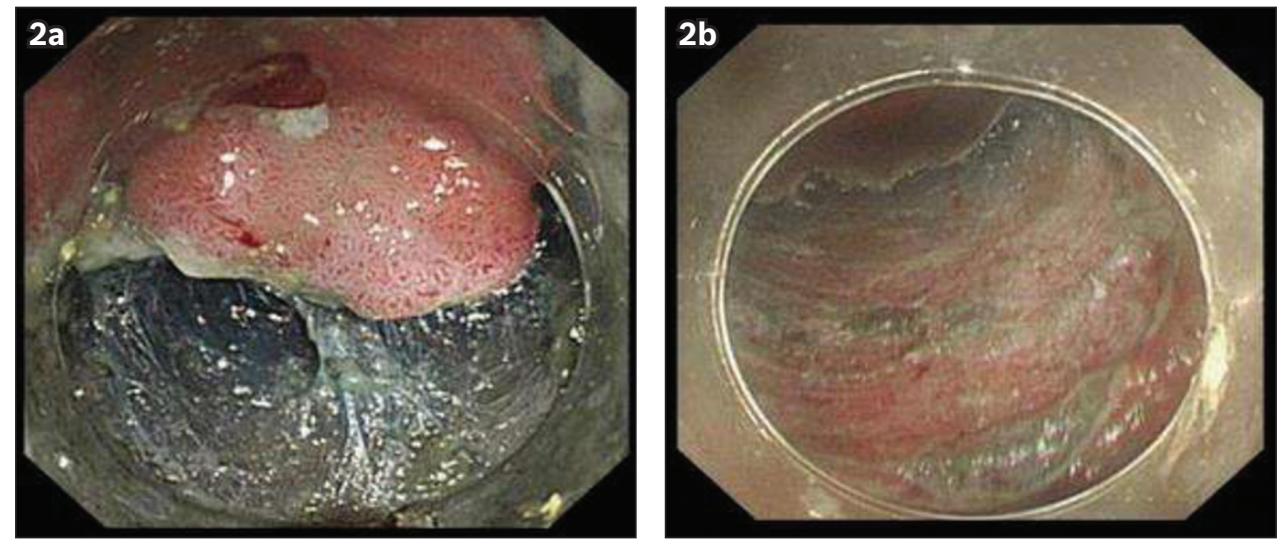

Fig. 2 Photographs show (a) the process of submucosal dissection and (b) the completed submucosal resection.

involvement. Such endoscopic features include ulceration and white coating, spontaneous bleeding, mucosal fold convergence and suspicious pit or vascular patterns on magnified views. As not all referring endoscopists were trained in identifying these features, this exclusion was not absolute. Biopsies were not performed in cases prior to endoscopic excision if image enhancement showed features typical of adenoma.

All ESD procedures were performed under sedation. Equipment used was: flexible endoscopes with a distal hood, the DualKnife ${ }^{\mathrm{TM}}$ electrosurgical knife (Olympus, Tokyo, Japan) and the Coagrasper ${ }^{\mathrm{TM}}$ Haemostatic Forceps (Olympus, Tokyo, Japan). Colonic lesions were raised using hyaluronic acid eye drops with indigo carmine. An incision of the mucosal layer was made using a DualKnife, followed by an incision of the submucosal plane using the same knife. Haemostasis of the submucosal plan was performed through direct coagulation with the DualKnife or with the haemostatic forceps. The resection was completed in some lesions using the Captivator ${ }^{\mathrm{TM}}$ II Single Use Snare (Boston Scientific, Natick, MA, USA) after adequate mucosal incision and submucosal dissection (Figs. 1 \& 2). More recently, the SB Knife ${ }^{\mathrm{TM}}$ Jr (Sumitomo Bakelite, Tokyo, Japan) was used for both submucosal dissection and haemostasis. After resection, further haemostasis was performed, followed by closure of the mucosal defect with Resolution ${ }^{\mathrm{TM}}$ Clips (Boston Scientific, Natick, MA, USA).

All specimens were pinned to demonstrate en bloc excision (Fig. 3), then sectioned at $2-3 \mathrm{~mm}$ intervals at the laboratory.

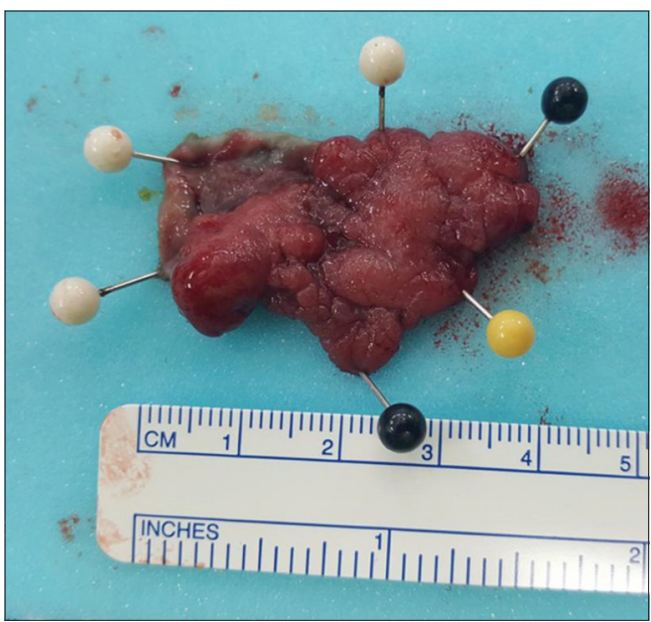

Fig. 3 Photograph shows an en bloc excision specimen pinned out for histology.

Lesions were classified histologically based on the World Health Organization classification. R0 resection was defined as an en bloc resection with clear resection margins histologically. Rx resection was defined as a piecemeal resection with resection margins that could not be assessed histologically.

In terms of post-procedure care, all patients were started on either a liquid or full diet. No routine blood tests or imaging were performed after the procedure. The majority of the patients were discharged on post-procedure Day 1 if there 
was no clinical evidence of complications such as bleeding and perforation.

\section{RESULTS}

The mean duration of our ESD procedures was 80.9 (range 21-300) minutes. The excised lesions had a median size of $2.00 \mathrm{~cm}$ and a mean size of 1.93 (range $0.5-4.5) \mathrm{cm}$. A longer procedure time was recorded for larger lesions (Table II). En bloc resection was used for $36(76.6 \%)$ out of 47 lesions that were resected. Piecemeal resection occurred more frequently in cases with larger lesions. 4 (7.8\%) cases were converted to surgery, mainly due to difficulty in raising the colonic lesions; however, not all lesions were found to be adenocarcinoma on histology.

On surveillance colonoscopy, 2 (4.3\%) patients had recurrence. Repeated excision showed that both lesions were non-malignant. In both of these cases, the ESD had been performed with piecemeal technique during the initial procedure due to the large size of the lesions, and margins were histologically involved during the first resection. 27 (57.4\%) patients had not yet undergone surveillance colonoscopy at the time of the study.

There were 3 (6.4\%) cases with complications from ESD. One of the patients developed pneumomediastinum, with a small pneumothorax that resolved with conservative management. Another patient had bleeding less than 24 hours after the procedure and required a repeat colonoscopy for haemostasis. The third case was converted to surgery due to a pinpoint perforation during ESD. Surgery was performed rather than attempting to close the defect, as there was difficulty raising the lesion and a suspicion of underlying malignancy. No mortality within 30 days following ESD has been reported in our institution thus far.

\section{DISCUSSION}

EMR was the standard for non-invasive treatment of colonic lesions before the introduction of ESD. ${ }^{(3,5)}$ However, various recent studies have demonstrated that ESD is becoming the preferred practice for larger lesions. ESD provides better R0 resection rates compared to EMR without exposing patients to the higher risks of surgery (laparoscopic or open resection). ${ }^{(8)}$ This study demonstrated the effectiveness of ESD for large colonic lesions.

Research by surgeons in Korea has described highly promising R0 and en bloc resection rates of $90.5 \%$ and $97.1 \%$, respectively. ${ }^{(9)}$ Another study conducted in a single European centre reported $\mathrm{R} 0$ and en bloc resection rates of $62 \%$ and $88 \%$, respectively, with ESD, which is more consistent with our data. ${ }^{(8)}$ There is no doubt that our results are inferior to those of Japan and Korea, showing the presence of a learning curve and the need for continued improvement of our techniques. Local challenges include the need for our endoscopists to have a more broadbased practice rather than subspecialise as pure endoscopists. A systemic review by Repici et al that examined 13 papers found a local recurrence rate of $0.07 \%$ for cases with R0 resection during a median of two years' follow-up. ${ }^{(10)}$ Studies done by the Japanese found five-year local recurrence rates of approximately $1.5 \% .{ }^{(6,11)}$ Based on our study, recurrence was associated with piecemeal
Table II. Endoscopic submucosal dissection results based on size of lesions.

\begin{tabular}{|c|c|c|c|}
\hline \multirow[t]{2}{*}{ Parameter } & \multicolumn{3}{|c|}{ No. (\%) } \\
\hline & $\begin{array}{l}\text { All } \\
(n=51)\end{array}$ & $\begin{array}{l}\leq 2 \mathrm{~cm} \\
(\mathrm{n}=32)\end{array}$ & $\begin{array}{l}>2 \mathrm{~cm} \\
(\mathrm{n}=19)\end{array}$ \\
\hline Conversion to surgery & $4(7.8)$ & $2(3.9)$ & $2(3.9)$ \\
\hline Perforation & $1(2.0)$ & $1(2.0)$ & $0(0)$ \\
\hline Unable to raise lesion & $3(5.9)$ & $1(2.0)$ & $2(3.9)$ \\
\hline \multicolumn{4}{|l|}{ Resection technique* } \\
\hline En bloc & $36(76.6)$ & $26(55.3)$ & $10(21.3)$ \\
\hline Piecemeal & $11(23.4)$ & $4(8.5)$ & $7(14.9)$ \\
\hline Mean procedure time (min) & 80.9 & 66.3 & 105.5 \\
\hline Complication* & $3(6.4)$ & $1(2.1)$ & $2(4.3)$ \\
\hline Perforation & $1(2.1)$ & $1(2.1)$ & $0(0)$ \\
\hline Bleeding & $1(2.1)$ & $0(0)$ & $1(2.1)$ \\
\hline Pneumomediastinum & $1(2.1)$ & $0(0)$ & $1(2.1)$ \\
\hline \multicolumn{4}{|l|}{ Location } \\
\hline Rectum and rectosigmoid & $15(29.4)$ & $10(19.6)$ & $5(9.8)$ \\
\hline Colonic & $36(70.6)$ & $22(43.1)$ & $14(27.5)$ \\
\hline \multicolumn{4}{|l|}{ Histology } \\
\hline Malignant & $3(5.9)$ & $1(2.0)$ & $2(3.9)$ \\
\hline Benign adenoma & $47(92.2)$ & $30(58.8)$ & $17(33.3)$ \\
\hline Neuroendocrine & $1(2.0)$ & $1(2.0)$ & $0(0)$ \\
\hline \multicolumn{4}{|l|}{ Margin involvement* } \\
\hline Involved & $2(4.3)$ & $0(0)$ & $2(4.3)$ \\
\hline Clear (R0) & $37(78.7)$ & $27(57.4)$ & $10(21.3)$ \\
\hline Unable to comment & $8(17.0)$ & $2(4.3)$ & $6(12.8)$ \\
\hline \multicolumn{4}{|l|}{ Recurrence* } \\
\hline No recurrence & $18(38.3)$ & $10(21.3)$ & $8(17.0)$ \\
\hline Positive recurrence & $2(4.3)$ & $1(2.1)$ & $1(2.1)$ \\
\hline Not due for scope & $27(57.4)$ & $19(40.4)$ & $8(17.0)$ \\
\hline
\end{tabular}

*47 lesions were endoscopically resected.

resection. Indeed, piecemeal resection has been observed to be the most influential factor in local recurrence for both ESD and EMR. ${ }^{(12)}$ Surveillance colonoscopy has been recommended one year after en bloc resection, while interval follow-up of six months is recommended for piecemeal resection. ${ }^{(6)}$

The long procedure time is one of the main drawbacks for ESD compared to EMR or polypectomy. A study conducted by a Korean group recorded a median time of 53 minutes for ESD, whereas another study by a Western country had a median time of 105 minutes. ${ }^{(13,14)}$ The present study had median time of 80.9 minutes. Our results also showed that larger lesions required a longer procedure time.

Our study had three patients with adenocarcinoma found in endoscopically resected specimens. In these cases, the decision for definitive surgical resection depends on the pathological features of the carcinoma. Lesions with deep submucosal invasion, tumour budding, high-grade tumour differentiation and lymphovascular invasion would have a higher risk of lymph node metastasis and thus mandate surgical resection. ${ }^{(15,16)}$ The need for such pathological evaluation also emphasises the value of en bloc resection of these lesions. 
A meta-analysis by Akintoye et al reported perforation and bleeding as the most common post-ESD complications. ${ }^{(17)}$ Another meta-analysis by Fujiya et al showed higher rates of complications following ESD compared to EMR (5.7\% vs. 1.4\%). ${ }^{(18)}$ The higher complication rate is one of the main reasons ESD is less commonly used in Western countries. In another study, rates of intra-procedure perforation for ESD were $4.5 \%$, while risk of bleeding was $1.3 \% .{ }^{(5)}$ Our study recorded $1(2.1 \%)$ patient with perforation during ESD who required immediate conversion to surgery. Despite the higher risk of perforation with ESD, some studies have argued that most perforations can be treated with endoscopic clipping, while conservative management with oral antibiotics can be used for delayed micro-perforations. ${ }^{(19)}$ Hotta et al stated that one criteria for conservative management of postESD perforation is the absence of peritonism. ${ }^{(20)}$

There were several limitations to our study. First, it was a retrospective study performed at a single institution and had a single-operator design. Additionally, not all patients who underwent ESD were followed up, as $52.9 \%$ of them were not due for surveillance colonoscopy. There has been a steady increase in the number of ESD procedures performed in our institution over time, which is likely secondary to referral patterns as well as increased awareness and trust in the technique of endoscopic resection. Correspondingly, fewer adenoma cases underwent surgical resection. According to Gotoda et al, proficiency in ESD requires experience of at least 30 cases. ${ }^{(21)}$ Hence, our experience in ESD is extremely basic compared to countries such as Japan. It is evident that we started with smaller lesions in the more distal colon and subsequently progressed to larger, more proximal lesions. A larger number of samples and longer period of time are needed to assess the long-term outcome of ESD at our institution. This report marks our observations and results upon reaching a milestone of 50 cases.

In conclusion, endoscopic resection of advanced colonic lesions using ESD is feasible but requires specific expertise. This capability needs to be further developed, as the technique can allow a greater possibility of R0 excisions and is ultimately less invasive than surgical resection.

\section{REFERENCES}

1. Cottet V, Jooste V, Fournel I, et al. Long-term risk of colorectal cancer afte adenoma removal: a population-based cohort study. Gut 2012; 61:1180-6.
2. Robertson DJ, Greenberg ER, Beach M, et al. Colorectal cancer in patients under close colonoscopic surveillance. Gastroenterology 2005; 129:34-41.

3. ASGE Technology Committee, Hwang JH, Konda V, et al. Endoscopic mucosal resection. Gastrointest Endosc 2015; 82:215-26.

4. Belderbos TD, Leenders M, Moons LM, Siersema PD. Local recurrence after endoscopic mucosal resection of nonpedunculated colorectal lesions: systematic review and meta-analysis. Endoscopy 2014; 46:388-402.

5. Ferreira J, Akerman P. Colorectal endoscopic submucosal dissection: past, present, and factors impacting future dissemination. Clin Colon Rectal Surg 2015; 28:146-51

6. Yamada M, Saito Y, Takamaru H, et al. Long-term clinical outcomes of endoscopic submucosal dissection for colorectal neoplasms in 423 cases: a retrospective study. Endoscopy 2017; 49:233-42.

7. Uraoka T, Parra-Blanco A, Yahagi N. Colorectal endoscopic submucosal dissection: is it suitable in western countries? J Gastroenterol Hepatol 2013; 28:406-14.

8. Sauer M, Hildenbrand R, Oyama T, et al. Endoscopic submucosal dissection for flat or sessile colorectal neoplasia $>20 \mathrm{~mm}$ : a European single-center series of 182 cases. Endosc Int Open 2016; 4:E895-900.

9. Lee EJ, Lee JB, Lee SH, et al. Endoscopic submucosal dissection for colorectal tumors-1,000 colorectal ESD cases: one specialized institute's experiences. Surg Endosc 2013; 27:31-9.

10. Repici A, Hassan C, De Paula Pessoa D, et al. Efficacy and safety of endoscopic submucosal dissection for colorectal neoplasia: a systematic review. Endoscopy 2012; 44:137-50.

11. Shigita K, Oka S, Tanaka S, et al. Long-term outcomes after endoscopic submucosal dissection for superficial colorectal tumors. Gastrointest Endosc 2016; 85:546-53.

12. Oka S, Tanaka S, Saito Y, et al; Colorectal Endoscopic Resection Standardization Implementation Working Group of the Japanese Society for Cancer of the Colon and Rectum, Tokyo, Japan. Local recurrence after endoscopic resection for large colorectal neoplasia: a multicenter prospective study in Japan. Am J Gastroenterol 2015; 110:697-707.

13. Farhat $S$, Chaussade $S$, Ponchon T, et al; SFED ESD study group. Endoscopic submucosal dissection in a European setting. A multi-institutional report of a technique in development. Endoscopy 2011; 43:664-70.

14. Kim JH, Baek IH, Kim KO, et al. Usefulness and feasibility of endoscopic submucosal dissection for colorectal tumor: a nationwide multicenter retrospective study in Korea. J Gastrointest Oncol 2016; 7:924-30.

15. Watanabe T, Itabashi M, Shimada Y, et al; Japanese Society for Cancer of the Colon and Rectum. Japanese Society for Cancer of the Colon and Rectum (JSCCR) Guidelines 2014 for treatment of colorectal cancer. Int J Clin Oncol 2015; 20:207-39.

16. Shimomura $\mathrm{T}$, Ishiguro $\mathrm{S}$, Konishi $\mathrm{H}$, et al. New indication for endoscopic treatment of colorectal carcinoma with submucosal invasion. J Gastroenterol Hepatol 2004; 19:48-55.

17. Akintoye E, Kumar N, Aihara H, Nas H, Thompson CC. Colorectal endoscopic submucosal dissection: a systematic review and meta-analysis. Endosc Int Open 2016; 4:E1030-44.

18. Fujiya M, Tanaka K, Dokoshi T, et al. Efficacy and adverse events of EMR and endoscopic submucosal dissection for the treatment of colon neoplasms: a meta-analysis of studies comparing EMR and endoscopic submucosal dissection. Gastrointest Endosc 2015; 81:583-95.

19. Yoon JY, Kim JH, Lee JY, et al. Clinical outcomes for patients with perforations during endoscopic submucosal dissection of laterally spreading tumors of the colorectum. Surg Endosc 2013; 27:487-93.

20. Hotta K, Shinohara T, Oyama T, et al. Criteria for non-surgical treatment of perforation during colorectal endoscopic submucosal dissection. Digestion 2012; 85:116-20

21. Gotoda T, Friedland S, Hamanaka H, Soetikno R. A learning curve for advanced endoscopic resection. Gastrointest Endosc 2005; 62:866-7. 